\title{
El sistema de sanciones por incumplimiento en el ámbito de la Comunidad Andina*
}

\author{
The System of Sanctions for Noncompliance \\ in the Ambit of the Andean Community
}

\begin{abstract}
María Ángela Sasaki Otani**
SumariO: I. Introducción. II. Generalidades del Tribunal de Justicia de la Comunidad Andina. III. Fortalezas y debilidades del TJCA. IV. El procedimiento sumario por desacato a las sentencias en acciones de incumplimiento. V. Conclusiones. VI. Bibliografía.
\end{abstract}

* Artículo recibido el 28 de febrero de 2011 y aprobado para publicación el 28 de septiembre de 2011.

** Licenciada en Derecho por la Pontificia Universidad Católica del Perú. Realizó estudios de posgrado en la Universidad de Buenos Aires (UBA), Argentina, y en la Universidad de la Comunidad Andina, Simón Bolívar, con sede en Quito, Ecuador. En julio de 2010 fue becaria del Instituto Max Planck de Derecho Internacional y Derecho Comparado, Heidelberg, Alemania. De 2008 a la actualidad se desempeña, en Quito, Ecuador, como funcionaria internacional en el Tribunal de Justicia de la Comunidad Andina (TJCA), como abogada asistente del magistrado por la República del Perú, doctor Ricardo Vigil Toledo. Las opiniones vertidas en el presente ensayo no involucran el criterio del Tribunal de Justicia de la Comunidad Andina (TJCA). 
RESUMEN: Hasta el momento, las sanciones por incumplimiento en materia económica en el ámbito de competencia del Tribunal de Justicia de la Comunidad Andina se han referido a dos aspectos solamente: 1) la autorización a los países miembros para gravar adicionalmente en un 5\% las importaciones de cinco productos del país incumplidor, o 2) limitar las normas de origen a través de la suspensión de emisión de certificados de origen con lo que el país miembro pierde la ventaja del Programa de Liberación al tener que pagar el arancel de terceros países. Sin embargo, ese sistema actual de sanciones ha devenido ineficiente, ya que en varios casos no existe interés por parte del país beneficiado (demandante) en aplicar las sanciones al país infractor, lo que da lugar a un doble incumplimiento, tanto del país demandado que no cumple la sentencia, como del país demandante que decide no aplicar las sanciones autorizadas por el TJCA. Por lo tanto, una de las opciones a fin de solucionar este impasse podría ser la imposición de multas coercitivas a los países miembros que incumplan una sentencia del TJCA, tal como sucede en la Unión Europea.

Palabras clave: sanciones económicas internacionales, multas coercitivas, acción de incumplimiento en contra de los países miembros, procedimiento sumario por desacato a las sentencias en acciones de incumplimiento, Comunidad Andina, Tribunal de Justicia de la Comunidad Andina, Procesos de integración regional.

ABSTRACT: So far, sanctions for non-economic matters in the purview of the Court of Justice of the Andean Community have addressed only two aspects: 1) approval from member countries to levy an additional $5 \%$ on imports of five products of the country defaulting or, 2) limiting rules of origin through the suspension of issuance of certificates of origin provoking that the member loses the advantage of the Liberalization Program by having to pay the tariff on third countries. However, the current system of sanctions has become inefficient, since in several cases, there is no interest by the recipient country (the applicant) to apply sanctions to the offending country, leading to a double failure of both the defending country not serving his sentence, and the requesting country that decides not to implement the sanctions authorized by the CJAC. Therefore, one of the options to resolve this impasse could be the imposition of penalty payments to members who violate a ruling by the CJAC, such as in the European Union.

Descriptors: International economic sanctions, Penalty payments, Breach Action against Member Countries, Procedure summary judgments for contempt of noncompliance, Andean Community, Court of Justice of the Andean Community, Regional integration processes.

RÉSUMÉ: Jusqu'à présent, les sanctions pour les questions non-économiques dans le ressort de la Cour de Justice de la Communauté Andine ont abordé deux aspects: 1) l'approbation des pays membres de percevoir un supplément de 5\% sur les importations de cinq produits du pays défaillant ou, 2) en limitant les règles d'origine à travers la suspension de la délivrance des certificats d'origine avec le député perd l'avantage du programme de libéralisation d'avoir à payer le tarif sur les pays tiers. Toutefois, le système actuel de sanctions est devenu inefficace, car dans plusieurs cas, il n'y a pas d'intérêt par le pays bénéficiaire (le demandeur) à appliquer des sanctions dans le pays fautif, conduisant à un double échec à la fois la partie défenderesse pas purgé sa peine, et le pays demandeur qui décide de ne pas appliquer les sanctions autorisées par le CJCA. Par conséquent, l'une des options pour résoudre cette impasse pourrait être l'imposition d'astreintes aux membres qui ne respectent pas une décision de la CJCA, comme dans l'Union Européenne.

Mots-Clés: Les sanctions économiques internationales, Astreintes, Breach mesures contre les pays membres; Jugements Résumé de la procédure pour outrage au tribunal de non-conformité, Communauté Andine, Cour de Justice de la Communauté Andine, Processus d'intégration régionale. 


\section{INTRODUCCIÓN}

La acción de incumplimiento constituye el mecanismo jurisdiccional que permite vigilar el cumplimiento de las normas que conforman el ordenamiento jurídico de la Comunidad Andina (en adelante CAN) por parte de los países miembros, siendo dicha acción una pieza clave en la construcción, desarrollo y vigencia del orden jurídico comunitario, dado que cuando los países miembros no cumplen las sentencias del Tribunal de Justicia de la Comunidad Andina (TJCA), se pone en juego la institucionalidad, existencia y eficacia del sistema andino de solución de controversias.

Lo que se trata entonces de establecer es una condena o sanción por la inejecución de una sentencia declarativa del incumplimiento, es decir, no es el incumplimiento en sí mismo considerado el que determina la imposición de la condena, sino la inejecución de un pronunciamiento judicial constatando tal incumplimiento. En tal sentido, se condena y se sanciona el desacato a la sentencia que declara el incumplimiento, cuando el país infractor no haya adoptado las medidas necesarias para la ejecución de la sentencia. Así, hasta el día de hoy las sanciones autorizadas por el TJCA por desacato a la sentencia que declara el incumplimiento se han referido a dos aspectos: i) la autorización a los países miembros para gravar adicionalmente en un 5\% las importaciones de cinco productos del país incumplidor, o ii) la limitación respecto a las normas de origen (suspensión de la emisión de certificados de origen con lo que el país miembro infractor pierde las ventajas del Programa de Liberación al tener que pagar el arancel de terceros países).

Por lo tanto, sugerimos reformar esta débil capacidad coercitiva del TJCA a fin de superar el problema del sistema actual de sanciones, ensayando para este propósito propuestas de reforma del Estatuto del Tribunal de Justicia de la Comunidad Andina. 


\section{Generalidades Del Tribunal DE JUSTICIA \\ DE LA COMUNIDAD ANDINA}

El Acuerdo de Cartagena fue firmado en 1969. Durante 10 años careció de un órgano jurisdiccional que resolviera sus controversias, y velara por el cumplimiento e interpretación de manera uniforme de las normas de su ordenamiento jurídico, hasta que por voluntad de los presidentes andinos se creó el "Tribunal de Justicia del Acuerdo de Cartagena”, mediante el Tratado de Creación del Tribunal de Justicia del Acuerdo de Cartagena del 28 de mayo de 1979.

La necesidad de contar con un órgano jurisdiccional propio que solucionase las controversias determinó que en 1971, la Comisión del Acuerdo de Cartagena, reunida en el VI Periodo Extraordinario de Sesiones, dejara constancia sobre dicha necesidad. Asimismo, los presidentes del Grupo Andino se reunieron en Colombia en 1978 y formularon la siguiente declaración:

Hemos llegado a la conclusión de que los avances registrados en el Proceso de Integración Andino demuestran la importancia de contar con un órgano jurisdiccional que controle la legalidad de las normas emanadas por la Comisión y la Junta, y dirima las controversias sobre el incumplimiento de las obligaciones de los países miembros e interprete los principios que conforman la estructura jurídica del Acuerdo. ${ }^{1}$

Dicho tratado debía entrar en vigencia con la última ratificación de los países miembros, lo que aconteció el 19 de mayo de 1983, cuando Venezuela depositó la última ratificación. Es así que el Tribunal de Justicia empezó a funcionar recién desde el 2 de enero de 1984, siendo los primeros magistrados designados los doctores Poppe por Bolivia, Sáchica por Colombia, Hurtado por Ecuador, Ortiz de Cevallos por Perú y Adueza por Venezuela. ${ }^{2}$

\footnotetext{
1 Barrientos Cazazola, Edgar, "El Tribunal de Justicia del Acuerdo de Cartagena. Antecedentes históricos, estructura y composición, competencias y procedimientos”, La integración, el derecho comunitario y el Pacto Andino, Quito, Universidad Andina Simón Bolívar, 1997, p. 88.

2 Idem.
} 
El 5 de enero de 1984, el presidente constitucional de la República del Ecuador, Osvaldo Hurtado, procedió a la instalación del Tribunal, en acto solemne en el que dicho mandatario señaló:

Los esfuerzos desplegados por los países andinos no han sido vanos. Hoy, en 1984, afortunadamente se han concretado en la iniciación de funciones de este Alto Tribunal de Justicia que, en sus actuaciones, consagra el principio de la supranacionalidad pues, sus Magistrados actúan con plena independencia de los países partes, y sus actos se fundamentan en los principios de la imparcialidad y la autonomía. Nuestra subregión ofrece, de este modo, un nuevo derecho en el ámbito latinoamericano, ya que el Tribunal tendrá las funciones de controlar la legalidad, solucionar los conflictos que se presenten entre las partes y ofrecer la interpretación unitaria del derecho. ${ }^{3}$

En tal sentido, somos de la opinión de que la creación tardía delTJCA, así como su puesta en funcionamiento en 1984 debilitó al proceso de integración andino en general ya que justamente la supranacionalidad viene determinada por la existencia de un Tribunal de Justicia de carácter permanente. Es así que la demora en la constitución del Tribunal se debió a una falta de voluntad política, causando un daño irreparable ya que elTJCA debió nacer en el mismo momento que se adoptó el Acuerdo de Cartagena que creó la Comunidad, en ese entonces denominado "Grupo Andino", incurriéndose en una omisión seria al no incluir un sistema eficaz de solución de controversias desde un inicio.

Cabe señalar que el Tratado que crea el Tribunal es un documento de derecho internacional público de igual jerarquía que el Acuerdo de Cartagena, por lo que su vigencia es paralela al Acuerdo y no es denunciable independientemente del mismo.

Asimismo, los magistrados del Tribunal son designados a propuesta de los países miembros, deben ser nacionales de cada uno de los países de origen, gozar de alta consideración moral y reunir las condiciones requeridas en su país para el ejercicio de las más altas funciones judiciales o ser jurisconsultos de notoria competencia. ${ }^{4}$

3 Ibidem, p. 89.

4 Salmón Gárate, Elizabeth, "Evolución institucional de la Comunidad Andina: perspectivas y problemas", Derecho comunitario andino, Lima, Fondo Editorial de la Pontificia Universidad Católica del Perú, 2003, p. 42. 
Los magistrados gozan de plena independencia en el ejercicio de sus funciones, y no pueden ejercer otras funciones profesionales ya sean éstas remuneradas o no, salvo las de docencia, gozando en el territorio de los países miembros de las inmunidades reconocidas por los usos internacionales y, en especial, por la Convención de Viena sobre Relaciones Diplomáticas del 18 de abril de 1961, y tienen, para estos efectos, jerarquía equivalente a los de los jefes de misión. ${ }^{5}$ Son elegidos por unanimidad de los países miembros de ternas presentadas por cada país miembro por un periodo de seis años.

Las competencias originales del TJCA son: las acciones de nulidad e incumplimiento, y la de la interpretación prejudicial. Las posteriores: "El recurso por omisión o inactividad, la función arbitral y la jurisdicción laboral fueron añadidas en virtud del Protocolo de Cochabamba modificatorio del Tratado de Creación del Tribunal de Justicia del Acuerdo de Cartagena”. ${ }^{6}$

Así, mediante el Protocolo de Cochabamba del 25 de agosto de 1999, se continuó con dichos cambios institucionales al incrementar las competencias del órgano jurisdiccional de la Comunidad Andina y darle un nuevo nombre: Tribunal de Justicia de la Comunidad Andina (TJCA).

Es así que, desde su creación, se dieron importantes cambios, entre los que se destacan los siguientes:

a) La conformación del Sistema Andino de Integración (en adelante SAI) mediante modificación del Acuerdo de Cartagena - Protocolo de Trujillo. ${ }^{7}$

5 Barrientos Cazazola, Edgar, "El Tribunal de Justicia del Acuerdo de Cartagena”, op. cit., p. 90.

6 El Protocolo Modificatorio del Tratado de Creación del Tribunal de Justicia de la Comunidad Andina fue suscrito en la ciudad de Cochabamba, Bolivia, a los 28 días del mes de mayo de 1996. En el mismo, se determina que: "El presente Protocolo Modificatorio entrará en vigencia cuando todos los Países Miembros que lo suscriban hayan depositado el respectivo instrumento de ratificación en la Secretaría General de la Comunidad Andina y haya entrado en vigencia el Protocolo Modificatorio del Acuerdo de Integración Subregional Andino (Acuerdo de Cartagena) aprobado en Trujillo, Perú el 10 de marzo de 1996”. Véase http:// www.comunidadandina.org/normativa/tratprot/cochabamba.htm.

7 El Protocolo Modificatorio del Acuerdo de Integración Subregional Andino (Acuerdo de Cartagena) fue suscrito en la ciudad de Trujillo, a los 10 días del mes de marzo del año de 1996. Este Protocolo entrará en vigencia cuando todos los países miembros del Acuerdo de Cartage- 
b) La incorporación de las funciones arbitral y laboral en el TJCA, así como el recurso por omisión (Protocolo de Cochabamba).

c) El amplio acceso de los particulares a la justicia comunitaria (Protocolo de Cochabamba).

d) La modificación en el tema de "anulación del veto" en la toma de decisiones. $^{8}$

e) La incorporación del comercio de servicios en los artículos 79 y 80 del Acuerdo de Cartagena (Protocolo de Sucre), ${ }^{9}$ ya que anteriormente el Acuerdo de Cartagena era sólo para el comercio de bienes y productos. ${ }^{10}$

Por lo tanto, actualmente el Tribunal es competente para conocer de cinco tipos de acciones: nulidad, incumplimiento, interpretación prejudicial, recurso por omisión o inactividad y demanda laboral; además

na que lo suscriben hayan depositado el respectivo instrumento de ratificación en la Junta del Acuerdo de Cartagena. Véase http: / / www.comunidadandina.org/normativa/tratprot/trujillo.htm.

8 Por lo tanto, se aprobó la Decisión 689 que modificó a la Decisión 486, a pesar del veto de Bolivia, mediante la cual la República del Perú implementó las modificaciones necesarias por la firma del TLC con Estados Unidos de América. Para materias específicas del Anexo I (tales como el Arancel Externo, las reformas al régimen común de propiedad intelectual, o la aprobación de propuestas presentadas por un país miembro), si bien no pueden ser aprobadas en primera instancia — prima facie — de presentarse voto negativo según el artículo 26 del Acuerdo de Cartagena; las propuestas que sean votadas negativamente serán devueltas al proponente y, en un plazo no menor de un mes ni mayor de tres, el proponente elevará nuevamente la propuesta a consideración de la Comisión con las modificaciones que estime oportunas de conformidad con el artículo 27 y, en tal caso, la propuesta así modificada se entenderá aprobada si cuenta con el voto favorable de la mayoría absoluta de los Países Miembros, en este caso, tres votos favorables. De no contarse con los tres votos favorables, la propuesta es desestimada.

9 Protocolo Modificatorio al Acuerdo de Integración Subregional Andino (Acuerdo de Cartagena), suscrito en la ciudad de Quito, Ecuador, a los 25 días del mes de junio del año de 1997. En el artículo 33 se señala lo siguiente: "Este Protocolo se denominará "Protocolo de Sucre" y entrará en vigencia cuando todos los Países Miembros hayan depositado el respectivo instrumento de ratificación en la Secretaría General de la Comunidad Andina”. Véase http: / /www. comunidadandina.org/normativa/tratprot/sucre.htm.

10 Véanse las siguientes Decisiones:

Decisión 439: Marco General de Principios y Normas para la Liberalización del Comercio de Servicios en la Comunidad Andina (11 de junio de 1998).

Decisión 659: Sectores de servicios objeto de profundización de la liberalización o de armonización normativa (14 de diciembre de 2006). 
tiene atribuida una competencia arbitral para dirimir las controversias que se susciten por la aplicación o interpretación de contratos o convenios suscritos entre órganos e instituciones del SAI o entre éstos y terceros.

\section{FORTALEZAS Y DEBILIDADES DELTJCA}

Entre algunas de las fortalezas del TJCA podemos mencionar las siguientes:

- Este órgano jurisdiccional es de carácter supranacional y permanente, contando con competencia territorial en los cuatro países miembros para conocer las siguientes controversias: la acción de nulidad, la acción de incumplimiento, la interpretación prejudicial, el recurso por omisión o inactividad, la función arbitral y la acción laboral. Así, el TJCA mediante sus sentencias ha dotado del mayor contenido posible al ordenamiento jurídico comunitario al interpretar y aplicar el derecho comunitario, bajo los principios del efecto directo, de la aplicación inmediata y de la supremacía del derecho comunitario andino. Hasta el año 2010, el Tribunal ha conocido de 1813 interpretaciones prejudiciales solicitadas por los jueces nacionales, 116 acciones de incumplimiento en contra de los países miembros, 50 acciones de nulidad, 9 procesos laborales y 6 recursos por omisión o inactividad de los órganos comunitarios, ubicándose como la tercera corte internacional más activa del mundo luego de la Corte Europea de Derechos Humanos y el Tribunal de Justicia de la Unión Europea.

- Existe celeridad en la resolución de los procesos, en comparación con otros tribunales internacionales, tales como, el Tribunal de Justicia de la Unión Europea (en adelante TJUE). A manera ilustrativa podemos mencionar que una interpretación prejudicial ante el TJCA demora un lapso promedio de dos meses, mientras que una consulta prejudicial ante el TJUE demora dos años. 
- El TJCA cuenta con una gran trayectoria, funcionando hace más de 20 años, siendo uno de los pocos tribunales supranacionales en el mundo (y con capacidad de autorizar sanciones a sus países miembros). Al respecto, cabe señalar que la gran barrera que divide los procesos de integración, en general, es la diferencia entre aquellos procesos de integración que tienen su base en la "supranacionalidad", ${ }^{11}$ con aquéllos — como era antes el Grupo Andino - basados en la "intergubernamentalidad", es decir, en la cooperación interestatal carente de toda transferencia o limitación parcial de soberanía a otro ente. Esta dicotomía se pone de manifiesto, especialmente, en la manera de afrontar el mecanismo para la solución de controversias: entre la opción de un Tribunal de Justicia permanente, con facultades supranacionales, o, el mecanismo tradicional, intergubernamental, del trato directo, los buenos oficios, la mediación y el arbitraje. ${ }^{12}$ Respecto a la supranacionalidad, podemos señalar que la misma se encuentra recogida en los procesos de integración de la Unión Europea, así como de la Comunidad Andina, ${ }^{13}$ lo que implica una aproximación seria a una integración no sólo económica, sino fundamentalmente política y social.

- El TJCA ha emitido importante jurisprudencia internacional sobre diversas materias, resultando ser un importante punto de referencia en el mundo académico y doctrinal (por ejemplo, un mayor acceso de los particulares a la justicia comunitaria en comparación con el TJUE, el "incumplimiento continuado", ${ }^{14}$ entre otros).

11 Como lo es ahora la Comunidad Andina, a partir de la entrada en vigor del Tratado de Creación del Tribunal de Justicia de la Comunidad Andina.

12 Al respecto, somos de la opinión que una de las características básicas de la supranacionalidad es la existencia de un tribunal permanente, cuyas sentencias sean obligatorias para todos los Estados miembros.

${ }_{13}$ El principio de supremacía se encontraba regulado en el Tratado del Carbón y del Acero y, si bien actualmente dicho tratado ya se encuentra derogado, la supremacía existe de manera jurisprudencial (véase casos “COSTA ENEL" y "Simmenthal”). En cambio, en la CAN, la supranacionalidad está expresamente regulada en el artículo 4o. del Tratado de Creación del TJCA, que señala claramente una obligación "de hacer" y "no hacer" para los Estados miembros.

14 Si la disposición nacional bajo examen sirve únicamente para "materializar determinada conducta que puede ser contraria o no a lo previsto en el orden comunitario, no cabe duda de que si tal norma se deroga o si se modifica, pero la conducta persiste o se transforma, 
Ahora, si bien el TJCA tiene fortalezas institucionales, debemos mencionar que existen grandes debilidades que devienen del proceso de integración en sí mismo, que dan lugar a ciertas limitaciones en su labor jurisdiccional como:

- Existe una débil capacidad coercitiva, ya que la Comunidad Andina aún cuenta con un mecanismo de sanciones con visos de "intergubernamentalidad”, esto último, porque quien decide -individual y soberanamente - aplicar o no la sanción "autorizada" son —en última instancia — sólo los países miembros (y no el TJCA).

- No se ha concluido el Reglamento de Arbitraje del TJCA: dicha función arbitral fue otorgada por el Protocolo de Cochabamba en 1996, es decir, hace más de 14 años, siendo ello de especial relevancia al incluir a los particulares y a los ciudadanos de la CAN (por ejemplo, en el caso que el contrato verse sobre derecho andino, de manera total o parcial).

- Falta de iniciativa en la difusión del derecho andino. Se deberían realizar "talleres itinerantes" en los cuatro países miembros, a fin de que aumenten las interpretaciones prejudiciales y las tareas y roles del TJCA. Una meta relevante debiera ser que Bolivia empiece, luego de más de 20 años, a solicitar regularmente interpretaciones prejudiciales, ya que desde la creación del TJCA ha solicitado menos de cinco. Ello incluye impartir talleres a los jueces nacionales, colegios de abogados, universidades, tribunales constitucionales, etcétera.

- Falta de legitimidad del proceso de integración andino, por parte del ciudadano andino y de la sociedad civil, ya que existe un gran desconocimiento en las empresas o en los estudios jurídicos respecto de las acciones posibles ante el TJCA, resultando ser los destinatarios finales del proceso de integración.

- Ausencia de la institución jurídica del acto aclarado, a fin que las interpretaciones prejudiciales no sean tan repetitivas. Como se sabe, elTJUE ha limitado en su jurisprudencia el alcance del "acto aclara-

haciéndose más gravosa o atemperándose en sus efectos, el incumplimiento subsiste con las características, se insiste, de un incumplimiento continuado". Véanse sentencias de los procesos 07-AI-98 y 118-AI-2003. 
do”, señalando algunos criterios desde 1963, con las sentencias Van Gend \& Loos (5 de febrero de 1963), y la Da Costa en Shaake (27 de marzo de 1963), donde señala que el juez nacional se sustrae de la obligación de enviar la consulta cuando "la cuestión planteada es materialmente idéntica a una que ya fue objeto anteriormente de una decisión prejudicial en un asunto análogo", aclarando luego en la sentencia CILFIT (6 de octubre de 1982) que no es necesario "una estricta identidad de las cuestiones en litigio”. Así, el TJUE (Asunto C-337/95) se ha pronunciado sobre el tema señalando que "cuando la cuestión planteada es materialmente idéntica a una cuestión que ya fue objeto de una decisión de carácter prejudicial en el marco del mismo asunto nacional", no es obligatorio para el juez interno el envío de la consulta. Contra todo pronóstico, la jurisprudencia del Tribunal de Justicia de la Comunidad Andina, en el Proceso 01 1P-87, publicado en la Gaceta Oficial núm. 028, de 15 de febrero de 1988 , se pronuncia en contra de la jurisprudencia europea, señalando que "la interpretación que en su sentencia establezca el Tribunal Comunitario rige tan sólo para el caso objeto de la consulta y, por tanto, no exime al juez nacional de la obligación de consultar en casos similares y análogos"; sin embargo, deja el campo abierto para introducir nuevos criterios, ya que en el Proceso 07-1P-89, publicado en la Gaceta Oficial núm. 053, del 18 de diciembre de 1989, señala que: "bien podría el Tribunal variar y aún cambiar su opinión, cuando encuentre razones justificadas para hacerlo".

- Ausencia de la opinión pública en las actividades públicas delTJCA, como por ejemplo en las audiencias públicas que se realizan dentro de los procesos de su competencia.

- Ausencia de voluntad política de los países miembros respecto a la integración andina en general, socavando ello las tareas delTJCA y su continuidad. Por ejemplo, ello se vio reflejado en la decisión de los países miembros de la CAN de no negociar en bloque con la Unión Europea un acuerdo de asociación.

- Momento de debilidad institucional en la Comunidad Andina, existiendo enfrentamientos políticos entre Bolivia-Perú (por la firma del TLC con Estados Unidos) y Colombia-Ecuador (conflicto en la frontera por la incursión colombiana en territorio ecuatoriano). 
Finalmente, luego de mencionar algunas de las debilidades, cabe señalar que nos concentraremos en el problema de la débil capacidad coercitiva del TJCA, por lo que se planteará una modificación del actual sistema de sanciones.

\section{EL PROCEDIMIENTO SUMARIO POR DESACATO \\ A LAS SENTENCIAS EN ACCIONES DE INCUMPLIMIENTO}

La acción de incumplimiento constituye el mecanismo jurisdiccional que permite vigilar el cumplimiento, por parte de los países miembros, de las normas que conforman el ordenamiento jurídico de la Comunidad Andina. Por lo tanto, el Tribunal se encuentra facultado para conocer de las acciones de incumplimiento que sean interpuestas por la Secretaría General, los países miembros, o los particulares afectados en sus derechos. A través de la acción de incumplimiento se ejerce el control del comportamiento de los Estados.

Hacia finales de la década de los noventa se han intensificado los desacatos a las sentencias del TJCA, particularmente por parte del Perú durante el gobierno del presidente Alberto Fujimori, quien amenazara con denunciar el Acuerdo de Cartagena. Así, dichos desacatos reflejan que el sistema de solución de controversias no cuenta con un mecanismo de incentivos para el cumplimiento de dichas sentencias, por lo que el sistema actual de sanciones resulta inoperante en la realidad. Es así que, en el caso de los fallos del Tribunal, si bien poseen un carácter vinculante y de estricto cumplimiento, existe una tendencia por parte de los Estados miembros a no acatarlos, lo que crea un problema en la existencia y eficacia del sistema de solución de controversias comunitario.

En principio, el concepto de sanción en la teoría contemporánea del derecho ha causado siempre cierto debate. Bentham, Austin y Bobbio ${ }^{15}$ dieron una definición funcional a la sanción, "la sanción como motivo para la obediencia, siendo las sanciones los únicos motivos útiles para la

15 Lara Chagoyán, Roberto, El concepto de sanción en la teoría contemporánea del derecho, México, Fontamara, 2004, p. 297. 
eficacia del derecho, teniendo - asimismo — como objeto indirecto, la formación del hábito de la obediencia”. ${ }^{16}$ Por otro lado, Kelsen señaló que "las sanciones están dispuestas en el ordenamiento jurídico para obtener un determinado comportamiento humano que el legislador considera deseable". ${ }^{17}$ Además, Garrido Falla considera a las sanciones "un medio represivo que se pone en marcha precisamente porque la obligación no se ha cumplido". ${ }^{18}$ Sin embargo, es a Bobbio a quien se debe el desarrollo de una "teoría promocional" del derecho, que ve a éste como una guía eficaz de la conducta a través del reconocimiento e incentivación de ciertas conductas, ${ }^{19}$ lo que sería aplicable al supuesto de tener que incentivar ciertas conductas en los Estados.

Ahora bien, a efectos del presente artículo, cabe resaltar que el Tribunal de Justicia de la Comunidad Andina propuso, en el Proyecto de Reforma del Estatuto, ${ }^{20}$ que se sustituyera el término de "sanciones" por el de "medidas coercitivas". Así, se entiende por "medida coercitiva" aquella medida sancionadora que obliga al pago de cierta cantidad de dinero calculada por unidad de tiempo, fundamentada en la mora del cumplimiento de una obligación (el cumplimiento de la sentencia).

Como señalamos anteriormente, se trata de establecer una condena por inejecución de una sentencia declarativa de un incumplimiento por un Estado miembro: no es el incumplimiento en sí mismo el que determina la imposición de la condena, sino la inejecución de un pronunciamiento judicial constatando tal incumplimiento. Se condena el hecho de que el país infractor no haya adoptado las medidas necesarias para la ejecución de la sentencia.

En tal sentido, el procedimiento sumario por desacato a las sentencias en acciones de incumplimiento se da cuando se trata de determinar el incumplimiento en que pudiera haber incurrido un país miembro, en la

16 Ibidem, p. 298.

17 Ibidem, p. 299.

18 Plaza Ventura, Patricia, Las sanciones comunitarias europeas: su aplicación a las empresas, Madrid, Edijus, 1999, p. 225.

19 Lara Chagoyán, Roberto, op. cit., pp. 285-304.

20 Documento informativo de la Secretaría General de la Comunidad Andina (SG/di 849), del 8 de junio de 2007, que contiene el Dictamen del TJCA con referencia al "Proyecto de reformas al Estatuto del TJCA". Al respecto, cabe señalar que las reformas al Estatuto no han sido aprobadas hasta el día de hoy. 
ejecución de una sentencia dictada en su contra en desarrollo de una acción de incumplimiento, por lo que este procedimiento resulta ser "accesorio" en el sentido que depende del proceso principal y determina la aplicación de una sanción por el desacato de la sentencia.

El país miembro que ha sido declarado en situación de incumplimiento dispone de noventa días, contados a partir de la notificación de la sentencia, "para adoptar las medidas necesarias para su cumplimiento". ${ }^{21}$ Transcurridos estos noventa días, el Tribunal de Justicia, de oficio, con fundamento en su propia información, o por denuncia de los países miembros, de los órganos comunitarios o de cualquier particular, puede iniciar un procedimiento sumario por desacato de la sentencia. Una vez emitido el auto de inicio del procedimiento y, cuando de la apertura se adviertan serios motivos de credibilidad acerca del incumplimiento de la sentencia, el Tribunal debe formular un pliego de cargos al país miembro sentenciado, en el que deberá consignarse la información que se tenga respecto del supuesto desacato. El país miembro dispone de cuarenta días para presentar sus descargos. Vencido este plazo, y una vez comprobado el desacato, el Tribunal dicta un auto que declara el desacato de la sentencia y en el que además se concede un plazo de treinta días para que la Secretaría General de la Comunidad Andina emita su opinión acerca de las sanciones que podrían aplicarse al país miembro. El Tribunal puede, además, convocar a una audiencia con el objeto de precisar lo que corresponda con respecto al tipo de sanciones. Finalmente, el Tribunal debe expedir un auto motivado que establezca las sanciones.

21 El artículo 4o. delTratado de Creación señala que: "Los Países Miembros están obligados a adoptar las medidas que sean necesarias para asegurar el cumplimiento de las normas que conforman el ordenamiento jurídico de la Comunidad Andina. Se comprometen, asimismo, a no adoptar ni emplear medida alguna que sea contraria a dichas normas o que de algún modo obstaculice su aplicación”.

ElTJCA reconoce su autoridad exclusiva para declarar judicialmente un incumplimiento mediante sentencia, siendo ésta de carácter meramente declarativo, donde se reconoce judicialmente la actitud contraria a derecho por parte del Estado condenado (artículo 23 del Tratado de Creación), por lo que su incumplimiento deriva en un procedimiento sumario que adelanta el propio Tribunal. 
El actual sistema de sanciones en la CAN se ha referido sólo a dos aspectos: i) la autorización a los países miembros para gravar adicionalmente en un 5\% las importaciones de cinco productos del país incumplidor, ${ }^{22} \mathrm{O}$ ii) se ha ordenado limitaciones respecto a las normas de origen (suspensión de la emisión de certificados de origen, perdiendo el país miembro la ventaja del Programa de Liberación pagando el arancel de terceros países). ${ }^{23}$ Sin embargo, ese sistema actual de sanciones ha devenido en ineficiente, ya que no existe interés en el país beneficiado de aplicar las sanciones al país infractor en varios casos, dando lugar a un doble incumplimiento, tanto del país demandado como del país demandante que decide no aplicar las sanciones autorizadas en la sentencia.

Así, en el Proceso 01-AI-97 del 20 de octubre de 1999, el TJCA ha señalado:

Que el desacato a un fallo de tal naturaleza constituye la más grave ofensa de cuantas puedan inferirse al Ordenamiento Comunitario pues lo resquebraja en su esencia al desconocer valores como el de respeto a los fallos que dirimen una controversia en última y definitiva instancia.

Que cuando se desacata una sentencia no se causa un daño particular o concreto que pueda ser reparado con una medida compensatoria en favor de quien

22 Véase como ejemplo la sentencia del Proceso 01-AI-97: "Determinar los límites dentro de los cuales los Países Miembros podrán restringir o suspender las ventajas del Acuerdo de Cartagena que al momento benefician a la República de Venezuela, autorizando a los Países Miembros de la Comunidad Andina, conforme a lo previsto en el artículo 27 de la Codificación del Tratado de Creación del Tribunal (Decisión 472 de la Comisión), para que a partir de la notificación de este auto, impongan un gravamen adicional del $5 \%$ a las importaciones de hasta cinco de los productos que en mayor volumen se efectúen a su territorio, procedentes y originarias deVenezuela. Los Países Miembros informarán al Tribunal, por intermedio de la Secretaría General de la Comunidad Andina, la lista de los productos objeto del gravamen sancionatorio, dentro de los veinte días siguientes a la comunicación de este auto a dicha Secretaría General. La presente sanción se mantendrá vigente hasta tanto la República de Venezuela demuestre fehacientemente ante el Tribunal que ha dado estricto cumplimiento a la sentencia del 11 de diciembre de 1997, proferida dentro del proceso 1-Al-97".

23 Cabe señalar que, la medida de suspensión de certificados de origen resulta mucho más onerosa que el gravamen adicional de 5\% (toda vez que la mayoría de productos goza ya de un $0 \%$ de arancel) ya que sin la aplicación de normas de origen hay que pagar el arancel para terceros países. Véase sentencia del Proceso 01-AI-97. 
sufre el daño, como podría suceder en los casos de restricciones unilaterales al comercio de ciertos productos, sino que se agravia de manera superlativa a todo el orden jurídico comunitario al desconocer o ignorar la fuerza vinculante de las sentencias, razón por la cual las sanciones que se impongan en estos casos no tienen por qué estar referidas ni guardar relación sólo con la gravedad del daño ocasionado por la conducta que dio origen a que se adelantara la acción de incumplimiento y se dictara la sentencia objeto del desacato, sino que, necesariamente, deben descansar en el hecho objetivo del incumplimiento de la sentencia del Tribunal de Justicia de la Comunidad Andina.

Que siempre y en todos los casos el incumplimiento de una sentencia del órgano jurisdiccional comunitario es de gravedad extrema, y que, como se puede deducir sin mayor esfuerzo dialéctico, es un hecho que afecta a todos los países miembros y a todos los órganos y entidades de la Comunidad al lesionar directamente el proceso de integración en el que la subregión viene empeñada desde hace más de 30 años (énfasis añadido).

En este sentido, las sanciones - gravamen adicional del 5\% $\%^{24}$ y la suspensión de certificados de origen — buscan sobre todo "compensar" a los demás países, por lo cual más que una "condena” resultan ser una "medida de equidad". ${ }^{25}$

24 El mecanismo sancionatorio está orientado a compensar, de alguna manera, a los demás países miembros, por lo cual más que una condena debe entenderse como un resarcimiento al resto de países de la Comunidad por el eventual daño causado por el país remiso; de ahí que, por lo general, los autos en los sumarios por incumplimiento de sentencias utilizan la siguiente fórmula o "medida de equidad": Determinar los límites dentro de los cuales los Países Miembros podrán restringir o suspender las ventajas del Acuerdo de Cartagena que al momento benefician al país remiso, autorizando a los países miembros de la Comunidad Andina, conforme a lo previsto en el artículo 27 del Tratado de Creación del Tribunal (codificado por la Decisión 472 de la Comisión), para que a partir de la notificación de este auto, impongan un gravamen adicional del 5\% a las importaciones de hasta cinco de los productos que en mayor volumen se efectúen a su territorio, procedentes y originarias de dicho país. Los Países Miembros informarán al Tribunal, por intermedio de la Secretaría General, la lista de los productos objeto del gravamen sancionatorio, dentro de los veinte días siguientes a la comunicación de ese auto a dicha Secretaría General. La sanción se mantendrá vigente hasta tanto el país remiso demuestre fehacientemente ante el Tribunal que ha dado estricto cumplimiento a la sentencia proferida dentro del proceso.

25 Novak Talavera, Fabián, "La Comunidad Andina y su ordenamiento jurídico”, Derecho comunitario andino, Lima, Fondo Editorial, 2003, p. 90. 
El Programa de Liberación de bienes tiene por objeto eliminar los gravámenes y las restricciones de todo orden que incidan sobre la importación de productos originarios del territorio de cualquier país miembro. Sin embargo, lo que resulta contradictorio es que se autorizan sanciones en la forma de "restricciones a las ventajas brindadas por el Acuerdo de Cartagena", constituyendo dicha sanción una infracción "autorizada" del Programa de Liberación, siendo el efecto real del mismo restringir el comercio comunitario (al igual que lo hizo la infracción). De esta manera "se sanciona con una infracción”, implicando ello un claro retroceso del Programa de Liberación en general. Es así que el sistema de sanciones puede afectar a operadores económicos no involucrados en la conducta objeto del incumplimiento y a uno de los principales objetivos del Acuerdo de Cartagena.

\section{Problemas del actual sistema de sanciones}

El sistema sancionatorio no satisface a todas las partes involucradas en la infracción de la norma andina, ya que en algunos casos dichas sanciones terminan por afectar a personas que directamente no han estado involucradas con las conductas que las motivan, ${ }^{26}$ desnaturalizándose los principios y presupuestos de la "teoría de la responsabilidad", por lo que resulta preciso buscar alternativas que —en lo posible - no causen efectos que incidan en su eficacia. Al respecto, en la teoría general del derecho existe el "principio de culpabilidad" (nulla poena sine culpa) que consiste en que debe existir un vínculo interno entre la infracción cometida y su autor. ${ }^{27}$ Es así que se debe sancionar siempre a quien incumple, es decir, al Estado, debiendo ser este último el único sujeto pasivo de las medidas sancionadoras de los países miembros, ya que es

26 Declaraciones del ministro de Comercio Exterior de la República del Ecuador, Tomás Peribonio: "No es racional que los esfuerzos de empresas exportadoras sean sistemática y exprofesamente afectadas por incumplimientos de otros". Agregó que, el sistema de sanciones es perverso y que es necesaria su revisión. Asimismo, la Federación Ecuatoriana de Exportadores (Fedexpor) señala que se debe establecer un sistema donde el Estado incumplidor sea quien reciba la sanción y no los exportadores ajenos al proceso sancionador. Fuente: www.mic. gov.ec y www.eluniverso.com.

27 Asunto Thyssen, p. 3740, y Asunto Estel, p. 1195. 
el único que puede caer en "incumplimiento" (artículo 23 del Tratado de Creación). De esa forma, la sanción debería recaer en el sujeto que incumplió, no sancionando tergiversadamente a sujetos particulares inocentes.

Además, en el sistema actual de sanciones es necesario delimitar la aplicación de sanciones económicas, a fin de asegurar la proporcionalidad de la sanción, afectando sólo a los sujetos que pueden estar siendo favorecidos por el incumplimiento, a título de corresponsabilidad del país miembro y del beneficiario de la infracción. En consecuencia, se debe aplicar la sanción en el sector en que se ha producido el incumplimiento, de lo contrario se afectará a los exportadores de productos que nada tienen que ver con la sentencia, a fin que quienes se hayan beneficiado o se beneficien de la acción u omisión del país infractor sean los primeros interesados en que el gobierno adopte las medidas conducentes a subsanar el incumplimiento. ${ }^{28}$

En el sistema sancionatorio actual, la aplicación de las sanciones autorizadas por elTJCA se deja a discrecionalidad de los países miembros, dándose el caso que, aun autorizadas las medidas por el TJCA, las mismas no son aplicadas por el país afectado por el temor a represalias. En tal sentido, una de las opciones a fin de solucionar este impasse podría ser la imposición de multas coercitivas a los países miembros que incumplan una sentencia delTJCA, tal como sucede en la Unión Europea.

En tal sentido, en el sistema sancionatorio actual, cuando la aplicación de las sanciones se deja a la discrecionalidad de los países miembros y ellos no aplican las sanciones autorizadas por el Tribunal (incumpliendo así la sentencia del Tribunal), dejan entrever características que distan de lo supranacional, acercándose más bien a lo que sería una integración

28 Mediante auto del 19 de mayo de 2004, el TJCA declaró a la República Bolivariana de Venezuela en desacato de la sentencia proferida el 27 de agosto de 2003, dentro de la acción de incumplimiento instaurada por la Secretaría General por violación del principio de Trato Nacional a los cigarrillos, tabacos y picaduras importados de los países miembros, dentro del Proceso 052-AI-2002. Posteriormente, mediante auto del 4 de agosto de 2004, el Tribunal determinó los límites mediante los cuales los Países Miembros pueden restringir o suspender las ventajas del Acuerdo de Cartagena a la República de Venezuela, siendo obligatorio imponer un gravamen del ocho al doce por ciento (8 al 12\%) sobre el valor de las importaciones de cigarrillos de tabaco rubio clasificados en la subpartida NANDINA 2402.20.20, procedentes y originarios del citado país. 
poco profunda que se parece más al sistema de la Organización Mundial del Comercio (OMC), ${ }^{29}$ ya que en general los países miembros tienen una gran reticencia a reconocer competencias sancionadoras a la institución comunitaria. ${ }^{30}$

Por ejemplo, al surgir una controversia dentro del Órgano de Solución de Diferencias (OSD) en la OMC, en caso de que un Estado no acatara las recomendaciones emitidas por el panel, éste puede llegar a conceder la suspensión de concesiones a favor del Estado vulnerado en contra del Estado considerado infractor, con el objeto de presionar a este segundo Estado para que revierta su política, a fin de que se encuentre nuevamente acorde con la normativa y los acuerdos de la OMC. Sin embargo, será discrecionalidad exclusiva del Estado beneficiado el suspender o no las concesiones autorizadas, situación que ha acarreado problemas importantes en la práctica, tal como sucede también en la Comunidad Andina, al no aplicar el país miembro beneficiado la sanción autorizada por el TJCA.

Así, tenemos el emblemático caso del Régimen de la importación, venta y distribución de bananos, ${ }^{31}$ donde la República del Ecuador solicitó la revisión de la política arancelaria en torno al banano por parte de la Unión Europea. El Órgano de Solución de Diferencias (OSD) emitió un dicta-

29 Somos de la opinión de que las retaliaciones autorizadas tipo OMC son características intergubernamentales, que distan de un Tribunal supranacional.

30 Asimismo, en la ALADI existe la Resolución núm. 114 del Comité de Representantes adoptada el 22 de marzo de 1990, que configuró el primer intento regional dirigido a establecer un procedimiento destinado a preservar el cumplimento de las normas del Tratado de Montevideo de 1980 y los compromisos contraídos en los acuerdos concertados por los países miembros. Esta Resolución tiene un alcance muy limitado pues sólo ha institucionalizado un "régimen de consulta" entre países miembros, en virtud del cual cualquiera de ellos podría solicitar su celebración al país que a su entender esté contraviniendo las medidas adoptadas. El procedimiento es de carácter facultativo y fija plazos para su iniciación y conclusión, a cuyo vencimiento sin haber logrado una solución satisfactoria, los Países Miembros sólo "podrán” recurrir al Comité de Representantes para que éste proponga fórmulas de carácter no vinculante para resolver la cuestión planteada y, en la práctica, el sistema resulta carente de toda utilización al no_representar un mecanismo que logre efectivamente resolver las cuestiones planteadas por los países miembros (énfasis añadido).

31 Solución de diferencias: Diferencia DS27. Comunidades Europeas Régimen de la importación, venta y distribución de bananos. http://www.wto.org/spanish/tratop_s/dispu_s/cases _s/ds27_s.htm. 
men mediante el cual autorizó suspender concesiones u otras obligaciones por un valor no superior a \$201.6 millones de dólares anuales respecto de la Unión Europea, ya que el nivel de anulación y menoscabo sufridos por el Ecuador se elevaba a dicho monto.

Asimismo, en el caso Bombardier vs. Embraer, ${ }^{32}$ en agosto de 2000 se autorizaron retaliaciones a favor de Canadá por el monto de \$344 millones de dólares anuales en contra de Brasil y, además, en diciembre del mismo año, se autorizó a Canadá aplicar contramedidas en contra de Brasil por un monto de $\$ 2.1$ billones de dólares (el monto más alto en la historia de la OMC), a razón de los subsidios ilegales otorgados por el Programa de Financiamiento a las Exportaciones Brasileras (Proex). ${ }^{33}$

En los dos casos arriba mencionados, los países beneficiados nunca aplicaron dichas autorizaciones por razones políticas y por su propia conveniencia, denotando ello su naturaleza de clásicas sanciones del derecho internacional público, tal como sucede con las medidas de retorsión, ${ }^{34}$ las represalias, ${ }^{35}$ las sanciones económicas, entre otras. ${ }^{36}$

32 Véase http://www.wto.org/english/tratop_e/dispu_e/222arb_e.pdf.

33 Materiales de enseñanza de la profesora Marie-France Paquet, University of Ottawa, p. 12. http://www.wto.org/spanish/news_s/news01_s/dsb_1feb01_s.htm.

34 Retorsión: es la forma más moderada de autotutela. Consiste, en general, en que un acto lícito pero poco amistoso, se contesta con otro acto también poco amistoso, pero lícito. Ejemplos de retorsión los tenemos en la publicidad del hecho ilícito para movilizar la opinión pública o en la retirada del exequátur a uno o a todos los cónsules del adversario, la llamada del jefe de misión acreditado en dicho Estado, la ruptura de relaciones diplomáticas, la imposición de restricciones en los visados de entrada, etcétera. Verdross, Alfred, Derecho internacional público, Madrid, Aguilar, 1982, pp. 400 y 401.

35 Represalias: actos que serían normalmente ilícitos pero que resultan conformes a derecho por la comisión de un acto ilícito anterior por el Estado contra el que las represalias van dirigidas. La licitud de las medidas de represalias supone la existencia previa de un ilícito internacional atribuible al Estado contra el que las represalias van dirigidas, de una parte, y de otra, una cierta proporcionalidad entre el ilícito y la represalia.

Carrillo Salcedo, Juan Antonio, Soberanía del Estado y derecho internacional, 1969, p. 212.

36 Entre otras modalidades de autotutela en el derecho internacional público tenemos la legítima defensa y la autoprotección o autotutela.

La legítima defensa: los Estados utilizan la fuerza para repeler una agresión producida por otro Estado. Con la firma de la Carta de las Naciones Unidas, el uso de la fuerza queda prohibido para los Estados, prohibición puntualmente establecida en el artículo 2o. (Principios de Naciones Unidas) inc. 4 de la Carta, donde postula: "Los Miembros de la Organización en sus relaciones internacionales, se abstendrán de recurrir a la amenaza o al uso de la fuerza contra la integridad territorial o la independencia política de cualquier Estado, o en cualquier otra 
Al respecto, Plaza Ventura ha señalado sobre la Unión Europea que:

La naturaleza jurídica del orden comunitario y su estructura ha influido de forma considerable en el sistema sancionador que dicho ordenamiento ha creado y desarrollado. Constituye un régimen sancionador más afortunado y diverso, según se dirija a los Estados miembros, funcionarios comunitarios o a las personas físicas o jurídicas, que el existente en el derecho internacional general. ${ }^{37}$

En la Comunidad Andina, a falta de voluntad política para cumplir las sentencias (por ambas partes, sea el país afectado y el infractor), resulta necesario fortalecer las medidas coercitivas, a fin de reforzar la credibilidad del sistema andino. Por otra parte, resulta imperativa una mejor difusión y publicidad de las sentencias del Tribunal, a fin de que exista una opinión pública fiscalizadora y controladora del cumplimiento de las sentencias por parte de sus respectivos países miembros, siendo lo ideal que haya cumplimiento sin necesidad de recurrir a una sanción.

Es menester señalar que las sentencias del Tribunal que declaran un incumplimiento por parte de un país miembro producen determinados efectos jurídicos inmediatos sobre las normas nacionales que contravengan el ordenamiento comunitario.

forma incompatible con los Propósitos de la Naciones Unidas". La excepción se presenta en el artículo 51 de la misma Carta, que dice: "Ninguna disposición de esta Carta menoscabará el derecho de legítima defensa, individual o colectiva, en caso de ataque armando contra un Miembro de las Naciones Unidas, hasta tanto que el Consejo de Seguridad haya tomado las medidas necesarias para mantener la paz y la seguridad internacionales. Las medidas tomadas por los Miembros en ejercicio del derecho de legítima defensa serán comunicadas inmediatamente al Consejo de Seguridad, y no afectarán en manera alguna la autoridad y responsabilidad del Consejo conforme a la presente Carta para ejercer en cualquier momento la acción que estime necesaria con el fin de mantener o restablecer la paz y la seguridad internacionales".

La autoprotección o autotutela: Las medidas de autotutela se plantean de una manera inevitable en una sociedad como la internacional, formada por Estados soberanos iguales en la que no existe ningún órgano superior que pueda asegurar coactivamente la aplicación del derecho internacional. En este medio descentralizado los Estados se ven a menudo abocados al establecimiento de medidas unilaterales de reacción frente a la comisión de actos ilícitos o lesivos por parte de otros Estados. Todos ellos son manifestaciones de la autotutela o la autoprotección por el Estado del propio derecho, por lo que constituye una reacción jurídica legítima frente a la previa vulneración por otros sujetos del derecho internacional.

37 Plaza Ventura, Patricia, Las sanciones comunitarias europeas, cit., p. 43. 
En primer lugar, en virtud de la primacía del derecho comunitario, ${ }^{38}$ una norma interna declarada contraria al orden jurídico andino no podría ser aplicada por las autoridades nacionales. En segundo lugar, de conformidad con el artículo 30 del Tratado del Tribunal, la sentencia de incumplimiento constituye título legal y suficiente para que los particulares puedan solicitar ante la jurisdicción nacional, la indemnización de daños y perjuicios que corresponda. ${ }^{39}$

En tal sentido, si bien la sentencia de incumplimiento no reviste un carácter constitutivo, ni tampoco puede anular el derecho interno, sí puede, en cambio, paralizar la aplicación del mismo, lo que implica la prohibición de pleno derecho de que las autoridades nacionales apliquen una disposición nacional reconocida como incompatible con el ordenamiento jurídico comunitario y, en todo caso, la obligación de adoptar todas las medidas para facilitar el pleno efecto del derecho comunitario. ${ }^{40}$

Luego de analizar los problemas que presenta el actual sistema de sanciones en la CAN, resulta interesante y necesario comparar el caso andino con el caso europeo, ya que no se podría hablar plenamente del sistema de sanciones andino sin antes tomar como elemento referencial el sistema de sanciones europeo, al ser la Unión Europea el proceso de integración más avanzado; mas ello no debe implicar tomar tal modelo de manera ciega y mecánica, dejando de lado las particularidades y singularidades de la subregión andina.

38 Las normas jurídicas comunitarias forman parte del ordenamiento jurídico interno de los países miembros y su incumplimiento implica también la trasgresión del derecho nacional.

Tangarife Torres, Marcel, "El sistema de solución de controversias en la Comunidad Andina. El papel de la Secretaría General de la Comunidad Andina”, Revista THEMIS, Perú, núm. 42, p. 120 .

39 No se tiene noticia que ello se haya dado en la Comunidad Andina. Asimismo, otro supuesto es lo que sucede en el caso de la Unión Europea, donde se estableció el principio de responsabilidad patrimonial de los Estados miembros por violaciones del derecho comunitario (sentencia Francovich del 19 de noviembre de 1991), determinando ello un deber de reparación de daños que abarca, en principio, la violación de cualquier norma comunitaria.

40 Véanse las sentencias de los Procesos 02-AI-97 y 051-AI-2000. 
En la Unión Europea, ${ }^{41}$ si la Comisión decide solicitar — a través de su potestad discrecional — que el Tribunal autorice una sanción, el importe de la multa coercitiva deberá tener por efecto que la sanción sea a la vez proporcionada y disuasoria, para lo cual la Comisión ha fijado una serie de criterios, entre los cuales se encuentran la gravedad de la infracción y su duración. ${ }^{42} \mathrm{Al}$ respecto, tenemos dos casos emblemáticos:

\section{A. La República Helénica}

En el Asunto C-387/97, la República Helénica fue condenada por no adoptar medidas para la eliminación de residuos tóxicos y, posteriormente, el país no dio el debido cumplimiento a la sentencia del Tribunal de Justicia de la Unión Europea (TJUE), alegando la falta de fondos. El TJUE, a través del proceso de cumplimiento de sentencia, aplicó una

${ }^{41}$ En la Unión Europea se introdujeron las "medidas coercitivas" en 1992 con el artículo 171 del Tratado de Maastricht, dándose la posibilidad de que el TJUE imponga al Estado que incumple la sentencia el pago de una suma a tanto alzado o de una multa coercitiva, determinando ello una regulación más fuerte y coactiva en el tema sancionatorio.

El Artículo 171 señala lo siguiente:

“1. Si el Tribunal de Justicia declarare que un Estado miembro ha incumplido una de las obligaciones que le incumben en virtud del presente Tratado, dicho Estado estará obligado a adoptar las medidas necesarias para la ejecución de la sentencia del Tribunal de Justicia.

2. Si la Comisión estimare que el Estado miembro afectado no ha tomado tales medidas, emitirá, tras haber dado al mencionado Estado la posibilidad de presentar sus observaciones, un dictamen motivado que precise los aspectos concretos en que el Estado miembro afectado no ha cumplido la sentencia del Tribunal de Justicia.

Si el Estado miembro afectado no hubiere tomado las medidas que entrañe la ejecución de la sentencia del Tribunal en el plazo establecido por la Comisión, ésta podrá someter el asunto al Tribunal de Justicia. La Comisión indicará el importe que considere adecuado a las circunstancias para la suma a tanto alzado o la multa coercitiva que deba ser pagada por el Estado miembro afectado.

Si el Tribunal de Justicia declarare que el Estado miembro afectado ha incumplido su sentencia, podrá imponerle el pago de una suma a tanto alzado o de una multa coercitiva.

Este procedimiento se entenderá sin perjuicio de lo dispuesto en el artículo 170”.

http: / / eur-lex.europa.eu/es/treaties/dat/11992M/htm/11992M.html.

42 Comunicación de la Comisión sobre la aplicación del artículo 171 del Tratado CE de 1996 y la Comunicación de la Comisión sobre el Método de cálculo de la multa coercitiva prevista en el artículo 171 del Tratado CE de 1997). 
multa diaria de 20.000 euros por cada día de retraso en construir el mecanismo de eliminación de residuos tóxicos. Sólo luego de ordenada la multa coercitiva, el gobierno griego procedió al cumplimiento. ${ }^{43}$

\section{B. El Reino de España}

Mediante sentencia en el Asunto C278/01 (Comisión de la Unión Europea/Reino de España), ${ }^{44}$ el TJUE declaró que en 1998 España había incumplido los valores límite fijados en la Directiva sobre las aguas de baño en relación con la calidad de las aguas de baño interiores. Al considerar que España no había ejecutado la sentencia de 1998, la Comisión interpuso en 2001 un recurso ante el Tribunal de Justicia con objeto de que se impusiera una multa coercitiva de 45.600 euros por cada día de retraso en la adopción de las medidas necesarias para cumplir esa sentencia. En primer lugar, el TJUE señaló que, con arreglo al derecho comunitario, España tenía la obligación de adoptar las medidas necesarias para ejecutar dicha sentencia. Aunque el Tratado CE no precisa ningún plazo para la ejecución de las sentencias, el Tribunal de Justicia declara que "esa ejecución debe iniciarse inmediatamente y concluir en el plazo más breve posible".

ElTribunal de Justicia fija la suma a tanto alzado o la multa coercitiva, constituyendo las propuestas de la Comisión sólo una referencia útil. El Tribunal de Justicia debe velar porque el importe sea adecuado a las circunstancias y proporcionado respecto del incumplimiento declarado y de la capacidad de pago del Estado miembro de que se trate, a la vez

43 En la sentencia núm. C-387/97 del Tribunal de Justicia de la Comunidad Europea, del 4 de Julio de 2000, se señaló: "Se condena a la República Helénica a pagar a la Comisión de las Comunidades Europeas, en la cuenta recursos propios de la CE, una multa coercitiva de 20.000 EUR por día de retraso en la adopción de las medidas necesarias para cumplir la sentencia Comisión/Grecia, antes citada, a partir del pronunciamiento de la presente sentencia y hasta la ejecución de la sentencia Comisión/Grecia, antes citada". Véase http: / / eur-lex.europa.eu /LexUriServ /LexUriServ. do? uri=CELEX:61997J0387:EN:HTML.

44 STJCE (Pleno), del 25 de noviembre de 2003. Asunto C-278/01, Comisión vs Reino de España. "Incumplimiento de Estado - Sentencia del Tribunal de Justicia por la que se declara un incumplimiento - No ejecución - Artículo 228 CE - Sanciones pecuniarias - Multa coercitiva - Calidad de las aguas de baño - Directiva 76/160/CEE”.

Véase http: / / eur-lex.europa.eu/LexUriServ/LexUriServ.do?uri=CELEX:62001J0278:E N:HTML. 
que pueda inducir al Estado miembro a poner fin, con la mayor brevedad, al incumplimiento.

Finalmente, el TJUE condena por segunda vez a un Estado miembro a pagar una multa coercitiva por no ejecutar la sentencia. Así, España fue condenada a pagar 624.150 euros al año por cada punto porcentual de zonas de baño interiores no conformes con los valores límites de la Directiva a partir de la temporada de baño de 2004. ${ }^{45}$ En ese sentido, la Unión Europea, al introducir la figura de la multa coercitiva, dotó al TJUE de una mayor capacidad coercitiva, teniendo ello, como consecuencia directa un mayor cumplimiento de las sentencias del TJUE.

\section{Propuestas de reforma al Estatuto del TJCA}

El artículo 27 de la Codificación del Tratado de Creación del Tribunal ${ }^{46}$ señala que el Estatuto debe precisar las condiciones y límites de la atribución del Tribunal para "ordenar la adopción de otras medidas si la restricción o suspensión de las ventajas del Acuerdo de Cartagena agravare la situación que se busca solucionar o no fuere eficaz en tal sentido”. El Estatuto vigente (Decisión 500 ${ }^{47}$ no contempla las condiciones y límites dentro de los cuales se podrían aplicar "otras medidas”, por lo que resulta necesario reglamentar la disposición contenida en el Tratado del

45 Cabe señalar que el Tribunal puede variar el monto de la sanción determinado por la Comisión, pero no puede superar la cuantía solicitada por aquélla (reformatio in peius). García, Ricardo Alonso, Derecho comunitario: sistema constitucional y administrativo de la Comunidad Europea, Madrid, Colección Ceura Centro de Estudios Ramón Areces, 1994, p. 466.

46 Decisión 472: Codificación del Tratado de Creación del Tribunal de Justicia de la Comunidad Andina. Se suscribe el presente Protocolo Modificatorio del Tratado de Creación del Tribunal de Justicia de la Comunidad Andina, en la ciudad de Cochabamba, Bolivia, a los 28 días del mes de mayo de 1996. El presente Protocolo Modificatorio entrará en vigencia cuando todos los países miembros que lo suscriban hayan depositado el respectivo instrumento de ratificación en la Secretaría General de la Comunidad Andina y haya entrado en vigencia el Protocolo Modificatorio del Acuerdo de Integración Subregional Andino (Acuerdo de Cartagena) aprobado en Trujillo, Perú, el 10 de marzo de 1996.

47 La Decisión 500: Estatuto del TJCA. Se suscribe en la ciudad de Valencia, Venezuela, a 22 de junio de 2001 y fue publicada en la Gaceta Oficial 680, del 28 de junio de 2001. 
Tribunal, reformando el artículo 119 del Estatuto. ${ }^{48}$ Así, el Tratado de Creación del Tribunal -modificado mediante el Protocolo de Cochabamba - estableció la posibilidad de que el Tribunal pudiera sancionar el desacato a sus sentencias en acciones de incumplimiento con otro tipo de sanciones distintas a las comerciales, las cuales debían ser precisadas en cuanto a sus condiciones y límites en el Estatuto correspondiente.

En efecto, el artículo 27 de la Codificación del Tratado de Creación del Tribunal dispone que:

Si la sentencia del Tribunal fuere de incumplimiento, el país miembro cuya conducta haya sido objeto de la misma, quedará obligado a adoptar las medidas necesarias para su cumplimiento en un plazo no mayor de noventa días siguientes a su notificación. ${ }^{49}$

Si dicho país miembro no cumpliere la obligación señalada en el párrafo precedente, el Tribunal, sumariamente y previa opinión de la Secretaría General, determinará los límites dentro de los cuales el país reclamante o cualquier otro país miembro podrá restringir o suspender, total o parcialmente, las ventajas del Acuerdo de Cartagena que beneficien al país miembro remiso. En todo caso, El Tribunal podrá ordenar la adopción de otras medidas si la restricción o suspensión de las ventajas del Acuerdo de Cartagena agravare la situación que se busca solucionar o no fuere eficaz en tal sentido. El Estatuto del Tribunal precisará las condiciones y límites del ejercicio de esta atribución. El Tribunal, a través de la Secretaría General, comunicará su determinación a los países miembros (énfasis agregado).

Sin embargo, al expedirse el nuevo Estatuto del Tribunal —mediante la Decisión 500 del Consejo de Ministros de Relaciones Exteriores__, no se reguló nada que permitiera precisar los límites y condiciones dentro de las cuales el Tribunal podría imponer sanciones distintas a las de tipo comercial, impidiendo que el Tribunal disponga la imposición de san-

48 El artículo 119 del Estatuto señala: "Si un País Miembro no acatare las obligaciones impuestas en la sentencia de incumplimiento, el Tribunal podrá sumariamente determinar como sanción, y conforme a lo previsto en el párrafo segundo del artículo 27 del Tratado, los límites dentro de los cuales el país reclamante o cualquier otro País Miembro podrá restringir o suspender, total o parcialmente, las ventajas del Acuerdo de Cartagena que beneficien al País Miembro remiso".

49 Véanse las sentencias en los Procesos 01-AI-96 y 07-AI-99. 
ciones diferentes a las mencionadas en el segundo inciso del artículo 27 trascrito, con lo cual el mandato contenido en el tercer inciso de dicha norma del Tratado ha quedado sin posibilidad de ejecución. ${ }^{50}$

Es así que resulta imperativo reformar el Estatuto del TJCA a fin de regular la posibilidad de imponer a los países que entren en desacato de las sentencias del Tribunal, sanciones de multa como una alternativa a las llamadas "sanciones de tipo comercial" y dejar en manos del Tribunal la definición, en cada caso, de la clase de sanción que se adecue más a las circunstancias específicas. Asimismo, transcurrido un tiempo prudencial sin que el país afectado por la sanción inicialmente impuesta haya cesado en la situación de incumplimiento, la sanción podría ser endurecida mediante la combinación de las multas con las sanciones comerciales.

\section{Dictamen del TJCA con referencia al "Proyecto de Reformas al Estatuto del Tribunal de Justicia de la Comunidad Andina”}

Mediante mandato del XV Consejo Presidencial Andino, ${ }^{51}$ contenido en el "Diálogo Presidencial sobre el Futuro del Proceso Andino de Integración y su Proyección en Sudamérica", se ordenó "revisar el mecanismo de sanciones del mismo, con miras a garantizar el cumplimiento automático de las sentencias del Tribunal de Justicia de la Comunidad Andina”.

Así, mediante el documento informativo SG/di 849, del 8 de junio de 2007, se dio a conocer el Dictamen del Tribunal de Justicia de la Comunidad Andina, con referencia al "Proyecto de Reformas al Estatuto del Tribunal de Justicia de la Comunidad Andina".

Este dictamen refleja la opinión o propuesta del órgano jurisdiccional, y no ha sido aprobado mediante Decisión, por lo que no tiene vigencia, quedando así pendiente la modificación del sistema de sanciones. En dicho dictamen, el TJCA sugirió lo siguiente:

50 En el tercer inciso del artículo 27 de la Codificación del Tratado de Creación delTribunal se señala que "El Estatuto del Tribunal precisará las condiciones y límites del ejercicio de esta atribución".

51 Quito, del 8 al 12 de julio de 2004.

Véase www.intranet.comunidadandina.org/Documentos/Presidencial/CP_15.doc. 
Artículo 115.- Medidas coercitivas

Si un país miembro no acatare las obligaciones impuestas en la sentencia de incumplimiento, el Tribunal podrá sumariamente determinar, conforme a lo previsto en el párrafo segundo del artículo 27 del Tratado, los límites dentro de los cuales el país reclamante o cualquier otro país miembro podrá restringir o suspender, total o parcialmente, las ventajas del Acuerdo de Cartagena que beneficien al país miembro remiso.

No obstante, el Tribunal podrá ordenar la adopción de otras medidas si la restricción o suspensión de ventajas del Acuerdo de Cartagena agravare la situación que se busca solucionar o no fuere eficaz en tal sentido.

En ejercicio de esta atribución, el Tribunal podrá ordenar las medidas que fueren necesarias para garantizar la cesación inmediata del desacato de la sentencia y de las obligaciones impuestas en ella. En particular, podrá ordenar la limitación, suspensión o restricción obligatoria y con efecto directo de ventajas o derechos derivados del ordenamiento jurídico de la Comunidad Andina. ${ }^{52}$ Dicha limitación, suspensión o restricción no podrá implicar la anulación de derecho alguno.

Al respecto, cabe señalar que existen diversos derechos y beneficios que el ordenamiento jurídico comunitario prevé, tales como, acceder en mejores condiciones a los préstamos que conceden los órganos que forman parte del sistema, lo que paralelamente conllevaría a que los países infractores se les limite, proporcionalmente, en esos derechos (suspensión de ventajas financieras ante la CAF).

Asimismo, podría caber la suspensión del derecho a participar en ciertos programas comunitarios o del derecho al voto, ya que solamente existe la suspensión del derecho al voto cuando no se pagan las cuotas oportunamente, así se podría sancionar al país infractor no participando con derecho a voto en determinados aspectos de la integración.

El TJUE y el Parlamento Europeo sugirieron que, aparte de las sanciones pecuniarias, se incluya "la suspensión del derecho a participar en ciertos programas comunitarios, beneficiarse de ciertas ventajas o acceder a determinados Fondos comunitarios”. Asimismo, en el artículo 88 del Tratado CECA se establece la posibilidad de sancionar económicamente a los Estados miembros mediante la suspensión, acordada por la Comisión, del pago de sumas debidas por la CECA al Estado miembro

52 García, Ricardo Alonso, Derecho comunitario..., cit., pp. 464 y 466. 
incumplidor. El fin aflictivo de la sanción consiste en la privación de un bien, que puede ser tanto patrimonial como jurídico, dirigido contra el sujeto infractor como consecuencia de la infracción comprometida. Además, en el Dictamen del TJCA se agrega que:

El Tribunal podrá asimismo imponer al país miembro remiso multas coercitivas hasta un importe de (corresponde su fijación a las instancias políticas de la Comunidad Andina; en opinión del Tribunal de Justicia, una cantidad razonable sería la de US\$20.000) quincenales, que se depositarán en una cuenta especial de la Secretaría General y que se destinarán a iniciativas para mejorar la aplicación del derecho comunitario en el país miembro multado. Las providencias mediante las cuales se imponen las multas coercitivas, junto con la liquidación a que haya lugar, constituirán título ejecutivo.

En la gradación del alcance de las medidas coercitivas contempladas en el presente artículo, el Tribunal tomará en cuenta los criterios de proporcionalidad a que hace referencia el artículo 116.

El Tribunal procurará asimismo que, en la medida de lo posible, los efectos de las medidas coercitivas limiten su alcance a quienes hayan incurrido, por acción u omisión, en el desacato de la sentencia, y a quienes se hayan beneficiado o se beneficien de dicho desacato.

EXPLICACIÓN: Se gradúan en función de las circunstancias de cada caso las medidas coercitivas que puede adoptar el Tribunal de Justicia, introduciendo como "última ratio" la posibilidad de imponer "multas coercitivas": El importe de tales multas, conviene subrayarlo, tendría como destino el propio Estado remiso, potenciando programas de actuación que tengan por finalidad precisamente mejorar la ejecución del derecho andino en el Estado en cuestión, particularmente para superar las insuficiencias presentes en el ámbito en el que se produjo el incumplimiento que está en el origen de la multa.

Sobre este punto es importante tomar en cuenta que el monto de la medida debe ser de tal magnitud que no deje a los Estados en posibilidad de fácilmente optar entre el incumplimiento y la sanción; de lo contrario la sentencia perdería su efecto persuasivo y sancionador propiamente dicho. 
Por otro lado, tomando en consideración la experiencia europea, ${ }^{53}$ tenemos que la Comisión de la $\mathrm{UE}^{54}$ estima que el importe de la multa coercitiva debe calcularse en función a una "fórmula general" 55 que contenga los tres criterios fundamentales o los denominados "coeficientes multiplicadores" que son: 1) la gravedad de la infracción; 2) la duración de la misma, y 3) la necesidad de asegurar el efecto disuasorio de la sanción para evitar la reincidencia, teniendo en cuenta la capacidad de pago del Estado miembro en cuestión (representada por el PBI y el número de votos de que se dispone en el Consejo de la UE).

Esta "fórmula general" de la Comisión de la UE denota un acercamiento mucho más serio y técnico a la problemática de la determinación del monto de la multa, contrarrestando así las críticas por falta de predeterminación normativa, ya que la norma europea tan sólo señalaba laxamente "un importe adecuado a las circunstancias", pero posteriormente fue la Comisión quien reglamentó ello y determinó los parámetros necesarios para la conformación más concreta de los montos de las multas coercitivas. Además, la Comisión señaló que dicha multa coercitiva constituirá "un ingreso suplementario marginal o atípico de la Comunidad", característica típica de las multas coercitivas.

Por otro lado, en el Dictamen del TJCA se señaló que las medidas coercitivas que podría adoptar el TJCA “se graduarán en función de las

53 El artículo 171 del Tratado CE, modificado por el Tratado de la Unión Europea, introduce la posibilidad de imponer sanciones a un Estado miembro que no haya ejecutado una sentencia de declaración de incumplimiento. La decisión última sobre la imposición de estas sanciones corresponde al Tribunal de Justicia de las Comunidades Europeas. No obstante, la Comisión, como guardiana de los Tratados, tiene en una primera fase un papel determinante en la medida en que le corresponde iniciar el procedimiento previsto por el artículo $171 \mathrm{y}$, si procede, someter el asunto al Tribunal de Justicia y pronunciarse sobre la imposición de una suma a tanto alzado o de una multa coercitiva por un importe determinado.

54 Véase la "Comunicación de la Comisión sobre la aplicación del Artículo 171 del Tratado CE”, Diario Oficial núm. C242 del 21 de agosto de 1996, pp. 0006-0008, y “Comunicación de la Comisión sobre Método de cálculo de la multa coercitiva prevista en el Artículo 171 del Tratado CE”, Diario Oficial núm. C063 del 28 de febrero de 1997, pp. 0002-0004.

55 La Comisión de la UE señala que el método de cálculo se resume en la "fórmula general" siguiente:

$\mathrm{Md}=(\mathrm{Tb} \times \mathrm{Cg} \times \mathrm{Cd}) \times \mathrm{n}$

en la que: $\mathrm{Md}=$ multa coercitiva diaria; $\mathrm{Tb}=$ tanto alzado de base; $\mathrm{Cg}=$ coeficiente de gravedad; $\mathrm{Cd}$ = coeficiente de duración; $\mathrm{n}$ = factor que tiene en cuenta la capacidad de pago del Estado miembro afectado. 
circunstancias de cada caso", al igual que en la UE que se señalaba "un importe adecuado a las circunstancias". Sin embargo, en la UE fue la Comisión quien concretó dicha aseveración a través de la "fórmula general" y el uso de coeficientes multiplicadores, lo que eventualmente haría falta en la CAN, en el supuesto que se reformara el Estatuto y se admitieran las multas coercitivas, ya que la aseveración delTJCA de que "se graduarán en función de las circunstancias de cada caso" resulta ser excesivamente gaseosa y difusa. Así, haría falta una reglamentación posterior que tome en cuenta ciertos factores, tales como la gravedad de la infracción, la duración de la misma y la capacidad de pago del Estado miembro.

Además, el TJCA agrega que es de la opinión que "una cantidad razonable sería la de US\$20.000 dólares americanos quincenales, que se depositarán en una cuenta especial de la Secretaría General y que se destinarán a iniciativas para mejorar la aplicación del Derecho Comunitario en el País Miembro multado". De esta manera, lo que propone el mismo TJCA es que el importe de las multas tenga como destino - indirecto - el propio Estado multado, siendo visiblemente contradictorio que la multa pagada vaya dirigida justamente al país que la pagó, aunque sea en otra especie.

Por otro lado, no creemos que sea adecuado limitar el monto de la multa a US\$20.000 quincenales, ya que podría suceder que dicho monto no sea suficiente o que sea excesivo, según las circunstancias de cada caso en concreto, además que el monto debería determinarse a través de la ponderación de la gravedad de la infracción, la duración de la misma y la capacidad de pago del Estado miembro. Por lo tanto, respecto a la determinación del monto de la multa, se debería dejar en manos del Tribunal, en cada caso, la determinación del monto que se adecúe más a las circunstancias específicas.

Sobre los criterios de proporcionalidad en la aplicación de medidas coercitivas se ha señalado que:

A efectos de la gradación de las medidas coercitivas previstas en el artículo anterior, el Tribunal en su auto y la Secretaría General, en la opinión que debe emitir, conforme a lo establecido en el artículo 113, tendrán en cuenta, según las circunstancias del caso, los tres siguientes criterios: 
a) La gravedad del incumplimiento, teniendo en cuenta, entre otros factores, la afectación del interés comunitario, el carácter objetivo del incumplimiento, ${ }^{56}$ la reincidencia, los efectos del incumplimiento sobre los objetivos de la Comunidad Andina, los perjuicios económicos o de otra naturaleza para los países miembros, particulares u operadores, y los esfuerzos realizados y las acciones adelantadas para corregir el incumplimiento después de la notificación de la sentencia. ${ }^{57}$

b) La persistencia y duración del incumplimiento.

c) La necesidad de garantizar la eficacia de las medidas coercitivas así como de evitar la reincidencia, teniendo en cuenta, entre otros factores, la ventaja que el país miembro remiso obtiene del incumplimiento de la sentencia y los efectos de dichas medidas en su economía.

El "incumplimiento objetivo" se da cuando de la simple comparación de una medida adoptada por un país miembro con el ordenamiento jurídico andino, resulta una trasgresión evidente. Se debe tomar en cuenta el concepto de incumplimiento flagrante definido en el artículo 57 de la Decisión 425 :

Se considerará flagrante un incumplimiento cuando éste sea evidente, en casos tales como la reiteración de un incumplimiento por parte de un País Miembro, previamente declarado por la Secretaría General, incluso cuando éste continúe mediante instrumentos formalmente distintos, o cuando el incumplimiento recaiga sobre aspectos sustantivos sobre los cuales la Secretaría General se hubiere pronunciado con anterioridad.

Por otro lado, el Tribunal de la Unión Europea (TJUE) calificó ello como un "incumplimiento no discutido".

Del análisis del Dictamen del TJCA, consideramos necesario que el Tribunal pueda ordenar la adopción de "otras medidas" cuando la restricción o suspensión de ventajas del Acuerdo de Cartagena agravare la situación que se busca solucionar o no fuere a eficaz en tal sentido, incluyendo la posibilidad de imponer al país miembro remiso de multas

56 Véanse las sentencias del Tribunal de Justicia de la Comunidad Andina en los Procesos 03-AI-96 y 01-AI-97.

57 Véase la sentencia del Tribunal de Justicia de la Comunidad Andina en el Proceso 02AI-97. 
coercitivas, limitando así los efectos de las medidas coercitivas a quienes hayan incurrido en el desacato de la sentencia, y a quienes se hayan beneficiado o se beneficien de dicho desacato, sin afectar a terceros "inocentes".

Es así que, mediante este Dictamen, el TJCA propone el fortalecimiento de su capacidad coercitiva, a fin de —en los hechos - obligar a los países miembros al cumplimiento de sus sentencias. Sin embargo, los países miembros a pesar de haber dado el mandato del XV Consejo Presidencial Andino ${ }^{58}$ de "revisar el mecanismo de sanciones del mismo, con miras a garantizar el cumplimiento automático de las sentencias del Tribunal de Justicia de la Comunidad Andina”, hasta el momento no han aprobado ningún cambio en el sistema actual de sanciones de la CAN. En ese sentido, es menester acotar que los intereses nacionales de cada país miembro deberían ceder paso a las prioridades subregionales y al interés comunitario.

\section{CONCLUSIONES}

El Programa de Liberación tiene por objeto eliminar los gravámenes y las restricciones de todo orden que incidan sobre la importación de productos originarios del territorio de cualquier país miembro. Sin embargo, lo que resulta contradictorio es que se autoricen sanciones en la forma de "restricciones a las ventajas brindadas por el Acuerdo de Cartagena”, constituyendo dicha sanción una infracción "autorizada" del Programa de Liberación, siendo el efecto real del mismo el de restringir el comercio comunitario (al igual que lo hizo la infracción). De esta manera "se sanciona con una infracción", implicando ello un claro retroceso del Programa de Liberación en general.

En tal sentido, el sistema de sanciones no está exento de críticas y falencias, debido a que además puede afectar a operadores económicos no involucrados en la conducta objeto del incumplimiento, así como a uno de los principales objetivos del Acuerdo de Cartagena.

58 Quito, del 8 al 12 de julio de 2004. 
Asimismo, el sistema sancionatorio no satisface a todas las partes involucradas en la infracción de la norma andina, ya que en algunos casos dichas sanciones terminan por afectar a personas que directamente no han estado involucradas con las conductas que las motivan, desnaturalizándose los principios y presupuestos de la "teoría de la responsabilidad”, por lo que resulta preciso buscar alternativas que - en lo posible - no causen efectos que incidan en su eficacia. Por lo tanto, se debe sancionar siempre a quien incumple, debiendo ser el Estado infractor el único sujeto pasivo de las medidas sancionadoras de los países miembros, ya que es el único que puede caer en "incumplimiento" (artículo 23 del Tratado de Creación delTJCA). De esa forma la sanción debería recaer en cabeza de quien incumplió, el Estado infractor, y no en sujetos particulares inocentes.

A fin de disminuir los efectos negativos del sistema actual de sanciones, se podría delimitar la aplicación de las sanciones económicas a un determinado sector productivo, a efectos de asegurar la proporcionalidad de la sanción, afectando así sólo a los sujetos que pueden estar siendo favorecidos por el incumplimiento del Estado infractor, a título de corresponsabilidad del Estado infractor y del beneficiario de la infracción. Por lo tanto, se podría aplicar la sanción en el sector en que se ha producido el incumplimiento, a efectos que quienes se hayan beneficiado o se beneficien de la acción u omisión del Estado infractor sean los primeros interesados en que el gobierno adopte las medidas conducentes a subsanar dicho incumplimiento.

Por otro lado, en el sistema sancionatorio actual, la aplicación de las sanciones se deja a discrecionalidad de los países miembros, dándose el caso que, aun autorizadas las medidas por el TJCA, las mismas no son aplicadas por el país afectado por el temor a represalias por parte del Estado infractor, por lo que se desvirtúan los fines para los que fueron autorizadas, quedando en un ámbito meramente político, no teniendo un carácter efectivo, proporcionado, ni mucho menos disuasorio del incumplimiento. En consecuencia, una de las opciones a fin de solucionar este impasse podría ser la imposición de multas coercitivas a los países miembros que desacaten una sentencia delTJCA, tal como sucede en la Unión Europea. 
Así, de la lectura del Dictamen del Tribunal de Justicia de la Comunidad Andina, con referencia al "Proyecto de Reformas al Estatuto del Tribunal de Justicia de la Comunidad Andina”, podemos señalar que, a través de la imposición de multas coercitivas por parte delTJCA, nacería una nueva obligación creándose un "deber nuevo" que sería el pago de la sanción pecuniaria por parte del país que no cumple la sentencia.

Por otro lado, creemos que resulta necesario regular "otras medidas alternativas" de sanción, a fin de que sea el mismo TJCA quien elija, según cada caso concreto, medidas que no sean contradictorias con el libre comercio entre los países miembros, como sucede con el sistema de sanciones actual que sólo cuenta con las dos opciones del gravamen adicional del 5\% y la suspensión de los certificados de origen (sanciones comerciales autorizadas que infringen el mismo Programa de Liberación).

Finalmente, entre las “otras medidas alternativas" de sanción podrían ser la privación o restricción de un derecho o expectativa preexistente (por ejemplo, la suspensión de ayudas financieras al país miembro infractor) aparte de la imposición de multas coercitivas.

De esa forma, las sanciones pueden tener un contenido patrimonial inmediato y directo, como la multa coercitiva consistente en la obligación de satisfacer una cantidad de dinero, o bien en la pérdida de una ventaja o una expectativa o en la privación de un derecho. En definitiva, en la privación de una situación subjetiva favorable constituida o amparada por el derecho comunitario, tomando en cuenta que este segundo tipo de sanciones provoca indirectamente un efecto patrimonial indudable, que podría tener un mayor efecto disuasivo, a fin de lograr un mayor cumplimiento de las sentencias delTJCA.

\section{BIBLIOGRAFÍA}

ARbUeT-Vignali, Heber, Las claves jurídicas de la integración: en los sistemas del MERCOSUR y la Unión Europea, Buenos Aires, Rubinzal-Culzoni Editores, 2004. 
Barrientos Cazazola, Edgar, "El Tribunal de Justicia del Acuerdo de Cartagena. Antecedentes históricos, estructura y composición, competencias y procedimientos”, La integración, el derecho comunitario y el Pacto Andino, Sucre, Universidad Andina Simón Bolívar, 1997.

CARrillo Salcedo, Juan Antonio, Soberanía del Estado y derecho internacional, Madrid, Editorial Tecnos, 1969.

Brewer CARÍAs, Allan R., "Derecho comunitario andino”, Derecho comunitario andino, Lima, Fondo Editorial de la Pontificia Universidad Católica del Perú, 2003.

GARCÍA, Ricardo Alonso, Derecho comunitario: Sistema constitucional y administrativo de la Comunidad Europea, Madrid, Colección Ceura, Editorial Centro de Estudios Ramón Areces, 1994.

Herrera Guerra, Jorge, "Las sanciones del derecho internacional”, Agenda internacional, año 5, núm. 10, 1998.

Lara Chagoyán, Roberto, El concepto de sanción en la teoría contemporánea del derecho, México, Doctrina jurídica contemporánea, 2004.

LECHELER, Helmut, Einführung in das Europarecht, Múnich, Verlag C.H. Beck, 2000.

Novak Talavera, Fabián, "La Comunidad Andina y su ordenamiento jurídico”, Derecho comunitario andino, Lima, Fondo Editorial del Instituto de Estudios Internacionales (IDEI) de la Pontificia Universidad Católica del Perú, 2003.

Plaza Ventura, Patricia, Las sanciones comunitarias europeas: su aplicación a las empresas, Madrid, Editorial Edijus, 1999.

RINCÓn EIZAGA, Lorena, "La legitimación del proceso de integración: Reto de la Comunidad Andina”, Agenda internacional, Lima, año 5, núm. 11, 1998.

Romano, Cesare P. R., "The Shift from the Consensual to the Compulsory Paradigm in International Adjudication: Elements for a Theory of Consent”, Journal of International Law and Politics, New York University, vol. 39, núm. 4, verano de 2007.

SÁCHICA, Luis Carlos, Introducción al derecho comunitario andino, San Francisco de Quito, Artes Gráficas Señal, 1985.

SAlmón GÁRATE, Elizabeth, "Evolución institucional de la Comunidad Andina: perspectivas y problemas”, Derecho comunitario andino, Lima, Fondo Editorial de la Pontificia Universidad Católica del Perú, 2003. 
TANGARIFE TORRES, Marcel, "El sistema de solución de controversias en la Comunidad Andina. El papel de la Secretaría General de la Comunidad Andina”, Revista THEMIS, Perú, núm. 42.

Vigil Toledo, Ricardo, "La solución de controversias en el derecho comunitario andino", en Lacarte, Julio \& Granados, Jaime (comp.), Solución de controversias comerciales e intergubernamentales: Enfoques regional y multilateral, Buenos Aires, 2004.

Verdross, Alfred, Derecho internacional público, Madrid, Aguilar, 1982.

La integración, el derecho comunitario y el Pacto Andino, Sucre, Universidad Andina Simón Bolívar, 1997.

Europa Recht, Berlín, Editorial Deutscher Taschenbuch Verlag, 2004.

Tabla de abreviaturas

CAF: Corporación Andina de Fomento.

CAN: Comunidad Andina.

CE: Comunidad Europea.

CECA: Comunidad Europea del Carbón y del Acero.

OMC: Organización Mundial de Comercio.

OSD: Órgano de Solución de Diferencias.

Proex: Programa de Financiamiento a las Exportaciones Brasileras.

TJCA: Tribunal de Justicia de la Comunidad Andina.

TJUE: Tribunal de Justicia de la Unión Europea.

SAI: Sistema Andino de Integración.

UE: Unión Europea. 